NBER WORKING PAPER SERIES

\title{
MANDATORY ACCESS PRESCRIPTION DRUG MONITORING PROGRAMS AND PRESCRIPTION DRUG ABUSE
}

\author{
Dhaval M. Dave \\ Anca M. Grecu \\ Henry Saffer \\ Working Paper 23537 \\ http://www.nber.org/papers/w23537 \\ NATIONAL BUREAU OF ECONOMIC RESEARCH \\ 1050 Massachusetts Avenue \\ Cambridge, MA 02138 \\ June 2017
}

We are grateful to the Agency for Healthcare Research and Quality (AHRQ) for funding support (1 R03 HS025014-01). Anca M. Grecu is grateful for the support of the Seton Hall University Research Council. Paloma Lopez de Mesa Moyano, Isaac Swensen, and Sabrina Terrizzi provided valuable comments on earlier versions of this study. The views expressed herein are those of the authors and do not necessarily reflect the views of the National Bureau of Economic Research.

NBER working papers are circulated for discussion and comment purposes. They have not been peer-reviewed or been subject to the review by the NBER Board of Directors that accompanies official NBER publications.

(C) 2017 by Dhaval M. Dave, Anca M. Grecu, and Henry Saffer. All rights reserved. Short sections of text, not to exceed two paragraphs, may be quoted without explicit permission provided that full credit, including ( $)$ notice, is given to the source. 
Mandatory Access Prescription Drug Monitoring Programs and Prescription Drug Abuse Dhaval M. Dave, Anca M. Grecu, and Henry Saffer

NBER Working Paper No. 23537

June 2017

JEL No. H0,I1,K0

\begin{abstract}
$\underline{\text { ABSTRACT }}$
Despite the significant cost of prescription ( $\mathrm{Rx})$ drug abuse and calls from policy makers for effective interventions, there is limited research on the effects of policies intended to limit such abuse. This study estimates the effects of prescription drug monitoring (PDMP) programs which is a key policy targeting the non-medical use of Rx drugs. Based on objective indicators of abuse as measured by substance abuse treatment admissions related to Rx drugs, estimates do not suggest any substantial effects of instituting an operational PDMP. We find, however, that mandatory-access provisions, which raised PDMP utilization rates by actually requiring providers to query the PDMP prior to prescribing a controlled drug, are significantly associated with a reduction in $\mathrm{Rx}$ drug abuse. The effects are driven primarily by a reduction in opioid abuse, generally strongest among young adults (ages 18-24), and underscore important dynamics in the policy response. Robustness checks are consistent with a causal interpretation of these effects. We also assess potential spillovers of mandatory PDMPs on the use of other illicit drugs, and find a complementary reduction in admissions related to cocaine and marijuana abuse.
\end{abstract}

Dhaval M. Dave

Bentley University

Department of Economics

175 Forest Street, AAC 195

Waltham, MA 02452-4705

and NBER

ddave@bentley.edu

Anca M. Grecu

Jubilee Hall 621

Stillman School of Business

Seton Hall University

South Orange, NJ 07079

anca.grecu@shu.edu
Henry Saffer

NBER

5 Hanover Square, 16th Floor

Suite 1602

New York, NY 10004-2630

hsaffer@gc.cuny.edu 


\section{INTRODUCTION}

Diversion of prescription ( $\mathrm{Rx}$ ) drugs for non-medical purposes is a serious public health concern, with over 50 million individuals or about $20 \%$ of the population (ages $12+$ ) having misused Rx drugs in their lifetime. Among illicit drug users, Rx drug abuse is second in prevalence only to marijuana, and among new initiates of illicit drugs, more than 1 in 4 have initiated with non-medical use of Rx drugs, fueling the concern that Rx drugs may be a gateway to harder illicit drug use especially for youth. ${ }^{1}$ Economic costs of prescription drug abuse have been estimated at about $\$ 80$ billion annually, stemming from lost productivity, criminal justice expenditures, drug abuse treatment, and health care costs (Florence et al. 2016).

To combat these problems, a popular state-level initiative has been to implement Prescription Drug Monitoring Programs (PDMP), electronic databases that track the prescribing and dispensing of controlled Rx drugs. PDMPs can provide critical information on the patient's prescription history to physicians and pharmacies, helping identify patients who may be doctor shopping, misusing Rx substances, and are at high risk of an overdose and would benefit from timely interventions.

Currently 49 states have an operational PDMP; however, in many of these states provider access and database queries are voluntary. Policymakers at the federal and state levels have recommended the implementation of PDMPs and specifically mandating their use by healthcare providers. The Centers for Disease Control and Prevention (CDC) highlights moving towards universal PDMP registration and utilization as one of the priority strategies for states to prevent prescription drug overdoses. The GAO report (US GAO 2009) also stressed that in order for PDMPs to be useful, providers and pharmacies must use the data.

\footnotetext{
${ }^{1}$ Based on the 2014 National Survey on Drug Use and Health.
} 
Starting in 2007, some states started enacting stronger statutes, enhancing their PDMPs with mandatory access provisions that require prescribers and/or dispensers to query the PDMP prior to prescribing or dispensing a controlled substance. Despite the call from policymakers towards universal utilization, rigorous evidence to inform the effectiveness of PDMPs is quite thin. Such evidence is especially important in light of the operating costs involved in rolling out and maintaining mandatory access provisions and the pushback from some providers who consider mandatory PDMP queries to be burdensome and an intrusion into their clinical practice (Haffajee et al. 2015). ${ }^{2}$

Most of the prior literature has found that PDMPs in general have limited or no effects on Rx drug abuse (Meara et al. 2016; Jena et al. 2014; Brady et al. 2014). However, these studies fail to differentiate between voluntary and mandatory programs. In states where providers have discretion in whether to refer to the PDMP prior to prescribing a controlled drug, utilization and query rates are very low, on the order of $14-25 \%$ (Alexander et al. 2015). Low prescriber utilization in voluntary states may explain why several prior studies find inconsistent and limited effects of PDMPs on indicators of Rx drug abuse. To our knowledge only two recent studies identify mandatory PDMPs though one (Buchmueller and Carey 2017) is limited in scope, examining only the Medicare population, and the second (Ali et al. 2017) finds limited impact based on self-reported measures of Rx drug misuse.

We contribute to this thin evidence base in several respects. First, we shift the lens specifically to mandatory access PDMPs. Second, we focus on admissions to substance abuse treatment facilities, an arguably better measure of the impact of these programs on misuse than

\footnotetext{
${ }^{2}$ Start-up costs for state PDMP implementation can vary from $\$ 450,000$ to $\$ 1.5$ million, with annual operating expenses ranging from $\$ 125,000$ to about $\$ 1$ million (Finklea et al. 2014). More recently, MA called for funding of $\$ 1.5$ to $\$ 3.7$ million for the roll-out of full mandatory use of the PDMP by providers (MDPH 2014).
} 
prescription drug sales, which is more commonly used in the previous literature. A reduction in sales does not mean a reduction in diversion and misuse if the prescription beneficiary reduces his own consumption but not the amount diverted to others. Substance abuse admissions directly related to Rx drugs also provide an objective counterpart to recent evidence based on selfreported survey data (Ali et al. 2017). Third, the conclusions of this research are easily generalized due to the length and national scope of our data. These data allow us to investigate the impact of mandatory PDMP provisions on a wide range of demographic groups, an important feature since regressions that impose the constraint of an equal effect for the entire population may mask heterogeneity and mistakenly conclude that the policy had little or no effect. Fourth, our data allow us to control for state specific trends. Failure to control for this important confounder could explain why previous literature found no effect on opioid poisonings (Buchmueller and Carey 2017). Fifth, we account for potential spillovers into the use of illicit drugs, an issue often overlooked both in the literature and by policy makers.

We find evidence that mandatory PDMP access laws are effective in reducing Rx drug abuse, and in particular opioid abuse, though there are important dynamics and heterogeneity in these effects, which we discuss. We also find some suggestive evidence that such mandatory access PDMP's have reduced treatment admissions related to cocaine and marijuana.

\section{BACKGROUND}

\subsection{Prescription Drug Epidemic}

The Rx drug abuse epidemic is fueled by opioid prescribing. Nearly 3 out of 4 overdoses are caused by opioid pain relievers, and these deaths have quadrupled since 1999 (Rudd 2016). Several factors, including the liberalization of rules in the 1990 s by state medical boards 
governing the prescription of opioid analgesics for chronic non-cancer pain, introduction of new and more aggressive pain management standards over this period, and the availability of new drugs (for instance, the market entry of OxyContin in 1996), ${ }^{3}$ have led to a dramatic increase in the use of opioid pain relievers over the past two decades (Manchikanti et al. 2010, 2011; Shatter Proof 2016). While this greater environmental availability and utilization of opioid pain relievers and other drugs has imparted benefits to many, they have also led to unintended consequences in the form of increased risk for diversion and overdose. The increase in opioid related deaths reversed the declining trend in mid-life mortality (Case and Deaton 2015).

Individuals can obtain Rx drugs for non-medical use through several channels including theft, street purchases, from a friend or relative, and "doctor shopping". The latter refers to patients obtaining prescriptions for controlled Rx drugs from multiple providers without the prescribers being aware of the other prescriptions. A recent CDC report finds that, while most non-medical users of Rx opioids obtain them from friends or family, physicians represent the leading source for those who are at highest risk of overdose; these individuals obtain Rx opioids through their own prescriptions (Jones, Paulozzi, and Mack 2014). Doctor shopping also constitutes an important indirect source for the end user by making up a key source of supply for street dealers (Inciardi et al. 2009); both physicians and pharmacists cite doctor shopping as the main source responsible for the diversion of prescription drugs from legitimate uses (National Center on Addiction and Substance Abuse 2005).

Additionally, changes on the market for Rx drugs may lead to potential spillovers into the use of illicit drugs. Heroin use has returned to levels not seen since the 1970s, and many heroin users now in treatment report beginning with Rx opioids. While recent evidence from the

\footnotetext{
${ }^{3}$ In 2010, the FDA approved an abuse-deterrent crush-resistant formulation of OxyContin (oxycodone), which results in a viscid substance if someone tries to dissolve the tablets in liquid and thus cannot be injected.
} 
NSDUH suggests a decline in prescription drug misuse over the prior year, past year heroin use and overdose-related mortality has been rising (Lipari and Hughes 2015). Thus, one concern is whether any success in reducing Rx drug abuse is leading to higher heroin use as opioiddependent individuals turn to heroin. On the other hand, regulations successfully preventing and reducing Rx abuse could reduce the pool of potential abusers who may subsequently substitute to heroin or other illicit drugs. Changes in Rx drug consumption may also affect the outcomes of concurrent users of both Rx drugs and illegal drugs, most likely cocaine (McCall Jones et al. 2017) and marijuana (Bachhuber et al. 2014). The pervasiveness of this problem provided the impetus for policy makers to consider legislation to curb prescription drug misuse.

\subsection{Prescription Drug Monitoring Programs}

State programs to monitor prescriptions of controlled substances were implemented starting in 1973. The programs were created to detect suspect flows of such substances and provide information to law enforcement but their scope was subsequently enhanced to provide information to physicians and pharmacists about their patients. In the absence of a PDMP, collection of Rx information would require a time-consuming manual review of pharmacy files. Recognizing the usefulness of collecting this type of information and making it available in real time to physicians in 2002, the Department of Justice started a program to support state initiatives of PDMP implementation. By 2003, the National Alliance for Model State Drug Laws published the Model Prescription Monitoring Program Act, which subsequently was followed by most states.

\subsection{Impact}

Despite calls from policymakers, rigorous evidence to inform the effectiveness of mandatory PDMPs is quite sparse. A recent review of the literature (Worley (2012) underscores 
the paucity of research in this area, and of the 10 US-based studies reviewed, only 3 have utilized a national sample (Simeone and Holland 2006; Reisman et al. 2009; Paulozzi, Kilbourne, and Desai 2011). The remaining studies are based on convenience samples or have evaluated programs in a single state, essentially comparing outcomes before and after implementation. The review concludes that the albeit sparse literature on PDMPs in the US is based on older data, which predated significant changes in PDMP laws, Rx drug abuse, and prescription rates, and exhorts the need for studies using more recent data. Many of the earlier PDMPs were mostly intended for law enforcement agencies, and providers typically did not have online access to this information (Radakrishnan 2013). Hence, the earlier results have limited relevance towards assessing the programs as they are currently implemented and structured, allowing providers and dispensers to access the historical data for a larger number of Schedule II and III drugs.

The evidence base from more recent studies is also quite limited. McDonald, Carlson, and Izrael (2012) analyze 135 million opioid prescriptions dispensed by retail pharmacies, and find that PDMPs have no significant effect. However, the results are based on cross-sectional evidence for a single year (2008), and do not distinguish between mandatory and voluntary PDMPs. Using Medicare Insurance claims data Jena et al. (2014) find that PDMPs have no effect on the number of individuals obtaining prescriptions from multiple providers. In fact, Haegerich et al. (2014) conclude that the past literature did not establish a robust effect of PDMPs on opioid prescribing. For most states over the sample period covered in these studies, physicians and dispensers had discretion in whether to refer to the PDMP prior to prescribing and dispensing a controlled drug. Low rates of prescriber utilization in such voluntary access states may explain the inconsistent and limited effects of PDMPs on indicators of Rx drug abuse in much of this prior literature. 
To the best of our knowledge, only two recent studies have focused specifically on mandatory-access PDMPs. Buchmueller and Carey (2017) find evidence that mandatory-access PDMPs are associated with various proxy measures of excessive opioid quantity and shopping behavior, but find no evidence of changes in opioid poisonings. However, the study is limited to the Medicare-covered population and cannot capture the impact on the most significant group of consumers, those aged 18-24 (who have the highest rates of Rx drug misuse in the population), and on those obtaining the Rx drugs through means other than their own prescription. Ali et al. (2017) utilize data from the National Survey on Drug Use and Health, and find no effect on participation measures of opioid misuse. They do, however, find some reduction in the number of days of misuse and in doctor shopping (defined as obtaining the Rx drugs from two or more doctors), though all of this evidence is based on self-reported information from survey respondents. ${ }^{4}$

We extend this seminal work in several respects. First, we utilize objective indicators of Rx drug abuse derived from administrative information on admissions to substance abuse treatment facilities. Second, the data are national in scope and cover all age groups and sociodemographics, allowing us to assess heterogeneity in the policy response and specifically examine whether the policy impacted outcomes among groups who are at highest risk for $\mathrm{Rx}$ drug misuse. This also imparts a degree of external validity to our estimates. Third, we account for response dynamics and confounding trends in the context of an event study framework, in order to isolate plausibly causal effects of the mandatory-access PDMPs.

\section{METHODOLOGY}

\footnotetext{
${ }^{4}$ This suggests that possibly there may be effects only at the intensive margin (frequency of misuse conditional on any reported misuse), though the study does not explicitly assess effects at this margin.
} 
We exploit variation in the timing of adoption of mandatory access stipulations, within a difference-in-differences (DD) framework, to estimate effects on objective indicators of Rx drug misuse, as measured by admissions to substance abuse treatment facilities.

To obtain a more precise understanding of the impact of PDMPs we employ an event study methodology, which takes into account the possible dynamic response of treatment admission. It is possible that by easing access to patient history, PDMPs lead first to an increase in treatment admissions, harvesting, and later, by reducing access to prescription drugs, to a reduction in treatment admissions. We therefore begin with the following specification that disentangles the timing of the policy response:

$$
Y_{s t}=\Sigma \beta_{T}(\text { Policy in effect during period } T)_{s t}+X_{s t} \delta+\gamma_{s}+\tau_{t}+\omega_{s} t+\varphi_{s} t^{2}+\varepsilon_{s t}
$$

The key outcome $(Y)$ represents treatment admissions per 10,000 individuals in a given state $s$ over year $t$. As described in the following section, we identify substance abuse treatment admissions related to various categories of Rx and illicit drugs, and estimate models for each drug category. Policy in effect during period $T$ is a vector of binary indicators equal to 1 in the year specified, such as 3 years before the new legal regime, 2 years before, the year prior to enactment, the year of enactment, one year after, 2 years after, and 3 or more years after enactment, and zero otherwise. The event study framework also helps assess the key identifying assumption underlying the DD analysis, that the control states (those which have not yet enacted mandatory access provisions for their operational PDMPs) are a valid counterfactual for the treated states (states with mandatory access provisions). We can indirectly test this assumption by examining whether trends in outcomes were similar across the treated and control states prior to policy adoption by examining the policy leads in the event study. 
Having identified the relevant timing of effect based on the event study, we then proceed to estimate the following standard DD specification:

$$
Y_{s t}=\beta \text { Policy }_{s(t-z)}+X_{s t} \delta+\gamma_{s}+\tau_{t}+\omega_{s} t+\varphi_{s} t^{2}+\varepsilon_{s t}
$$

In equation (2), Policy denotes an indicator for when a given state enacted mandatory-access provisions for an operational PDMP, with $z$ representing the first year of impact. The parameter of interest, $\beta$, summarizes the average effect of a mandatory-access PDMP over this postadoption period.

In all specifications, we control for a series of potential confounding factors. The vector $X$ represents a set of time-varying variables correlated with treatment admissions: unemployment rate, income per capita, percent male, percent Black, percent other race, (White race omitted), age structure of population over 12, the proportion of state population over 18 covered by Medicaid, the proportion of state population over 18 covered by Medicare, and the number of physicians per 10,000 people. These variables improve identification by acting as proxies for state unobservable characteristics correlated with both treatment admission rates and legislative changes, such as greater state interest in health policy, which would affect the likelihood of adoption of health regulations.

Another possible source of confounding is the adoption of other state regulations targeting prescription drug abuse. The most likely offenders are ID laws, which require or permit a pharmacist to ask for identification prior to dispensing a controlled substance and physical examination requirement (PER). The latter regulation requires healthcare providers to either conduct a physical exam of the patient, or have a bona fide patient-physician relationship that includes a physician examination, prior to prescribing Rx drugs. We concentrate on a period of 
time, 2003-2014, which excludes most instances of PER adoptions, and we include controls for both types of laws.

All specifications further include state fixed effects, $\gamma$, which control for any stable unmeasured heterogeneity across these areas (for instance, secular differences resulting from unmeasured cultural factors, or physician practice styles specific to each area). Models also include time fixed effects, $\tau$, which capture unobserved trends in drug use and related factors common to the entire population, such as changes in federal-level healthcare policies and overall economic conditions. All models include linear and quadratic state specific trends $\left(\omega_{s} t ; \varphi_{s} t^{2}\right)$, which control for differential trends in drug use in adopting states relative to the control states that might affect the likelihood of state policy adoption. Conditional on state and year fixed effects, and state-specific trends, the policy effects are identified from year-by-year changes in legislation within states, after controlling for shocks common to all states and state-specific factors and trends affecting treatment admissions.

In addition, we consider the possibility of heterogeneous responses due to unobserved group or geographic-specific factors that affect the relative importance of the costs vs. perceived benefits of Rx abuse. These unobservables include differences in baseline prevalence rates, information, health insurance, risk preferences, discount rates and sentiment, and may be systematically related to observable demographic variables. The prevalence of Rx drug abuse along with the reasons for non-medical use of Rx drugs differ by age. Some individuals use prescription painkillers non-medically because they became addicted after using the painkillers for legitimate reasons. This is more likely to be the case among adults (over 35 years of age) (Nedeljkovic, Wasan, \& Jamison 2002). On the other hand, teenagers might engage in illicit use of various substances (among other reasons) to get "high" and to fit in with their peers (Wood, 
Read, Palfai, and Stevenson 2001; Torabi et al. 1993). College students or young adults might use stimulants to help stay awake and concentrate for their studies (Teter, McCabe, Cranford, Boyd, \& Guthrie 2005). To investigate these effects, we further disaggregate admissions across geographic area-year-group cells, and consider differential responses across relevant age groups, across urbanicity, across different categories of abused substances, and across source of referral for the treatment admission.

All regressions are weighted by the state level population in the relevant age group (Angrist and Pischke 2009). Standard errors are clustered at the state level to allow for an arbitrary autocorrelation process within areas (Bertrand, Duflo, and Mullainathan, 2004).

\section{DATA}

The analyses are based on administrative data from the Treatment Episode Data Set (TEDS), which contain information on demographic and substance abuse characteristics of all admissions to treatment facilities that receive any federal funding (covering $67 \%$ of the entire population of treatment admissions to all known providers; Dave and Mukerjee 2011). We collapse the data into admission counts for each primary substance of abuse of interest at the state-year-age group level. ${ }^{5}$

We first consider several types of prescription drugs grouped together: opiates and synthetics, stimulants, benzodiazepines, non-benzodiazepine tranquilizers, barbiturates, inhalants. ${ }^{6} \mathrm{We}$ also consider opiates and synthetics separately as these constitute the main source of the increased prescription drug abuse. ${ }^{7}$ We also consider benzodiazepine and stimulants other

\footnotetext{
${ }^{5}$ Fewer than $2 \%$ of observations have missing values for the primary substance problem.

${ }^{6}$ See Appendix for details on the specific drugs included in each category.

7 The Rx drug abuse epidemic is fueled by opioid prescribing, with nearly 3 out of 4 overdoses caused by opioid pain relievers.
} 
than amphetamines separately. Benzodiazepines, also known as tranquilizers, are one of the most often prescribed medications in the United States (see Valium, Xanax, Ativan) because they are used to treat common conditions such as anxiety and insomnia. They also constitute one of the most commonly abused classes of drugs. The 2002-2005 National Survey on Drug Use and Health data indicated that the lifetime non-medical use of benzodiazepines is approximately $4 \%$ (Maxwell 2006). Stimulant methylphenidate (e.g., Ritalin and Concerta) is prescribed to treat attention-deficit hyperactivity disorder (ADHD). Furthermore, misuse of these drugs is common among youths, with rates estimated between 5 and 35\% among college students (Clemow and Walker 2014).

In addition, we consider the possibility of spillovers on other markets. Specifically, we also analyze whether, and the extent to which, mandatory PDMP provisions impacted treatment admissions for heroin, marijuana, cocaine, alcohol, or over-the-counter medication abuse.

The dates PDMPs became operational and enactment dates of mandatory access provisions are obtained from the National Alliance for Model State Drug Laws. The first adoption of a mandatory PDMP occurred in Nevada in 2007. We concentrate on the period between 2003-2014. The end of the period is imposed by the availability of data from TEDS. The beginning of the analysis sample was chosen to allow a sufficiently long pre-adoption period. Notably in 2003, the National Alliance for Model State Drug Laws published the Model Prescription Monitoring Program Act, which subsequently was followed by most states. Thus, the laws considered in this study over our sample period are quite homogenous across states. Figure 1 identifies PDMP and mandatory access provision adoptions during the period investigated. 
Data regarding ID laws and PER laws were compiled from information reported by the National Conference of State Legislatures and the Centers of Disease Control and Prevention, and cross-validated through the review of individual state legislatures and the Federation of State Medical Boards. Data on gender composition and the age and race structure of the state's population come from the National Center for Health Statistics. The unemployment rate and the income per capita are obtained from the Bureau of Economic Analysis (BEA). The proportion of population over 18 covered by Medicaid, and the proportion of population over 18 covered by Medicare are derived from the Current Population Survey (CPS). Information on physician density comes from the Area Health Resource Files (AHRF).

Table 1 presents summary statistics for these variables for the period preceding legislative changes, separately by adoption status in the following year. The upper panel reports summary statistics for the period preceding the adoption of PDMPs. The lower panel concentrates on the period preceding the adoption of mandatory access provisions. It is validating that variables describing the demographic, economic and health care environment are balanced between the two groups of states. Adopting states appear to have somewhat higher rates of treatment admissions for prescription drugs, albeit the difference is not statistically significant at conventional levels. ${ }^{8}$ Overall, the descriptive statistics do not suggest any evidence that PDMP adopting states, and specifically those that adopted mandatory-access provisions, are significantly different from non-adopting states.

\section{RESULTS}

\footnotetext{
${ }^{8}$ Because our empirical strategy assumes exogeneity conditional on state and year fixed effects and state specific trends, the t-statistics are derived conditional on these variables.
} 


\subsection{Preliminary analysis}

While it is validating that the means presented in Table 1 do not show any systematic differences between the treated and control states, we first assess the "parallel trends" assumption underlying the DD analyses in Figure 2, which represents graphical evidence of preand post-adoption trends. Visually, it appears that PDMP adopting states were on a steeper increasing trend in treatment admissions than non-adopting states, suggesting that failure to control for differences in trends could bias the estimates. In addition, there is some evidence of harvesting. Immediately following a PDMP becoming operational, there appears to be an increase in admissions followed by a reversal to the previous trend. Perhaps Rx abuses that would have been identified anyway are identified sooner when patient history data are easier to access. In the subsequent analysis, we concentrate on the second lag following adoption.

On the other hand, Figure 2 suggests that adopters of mandatory access provisions were very similar to states having a PDMP but who did not adopt such provisions. The second panel of Figure 2 also presages our main result that these mandatory access provisions effectively reduced Rx drug abuse. Prior to enactment, adopting and non-adopting states were on similar trend paths, but admissions for Rx drug abuse markedly declined in the adopting states postenactment. Thus, we can be reasonably confident that the adoption of these mandatory access provisions is exogenous in the sample of states with an operational PDMP, indicating the intent to treat.

Second, we perform an event analysis using the specification described in equation (1) and present the estimates in Figure 3. This strategy allows us to visualize the impact year by year. We find no evidence of any effects before a PDMP (Figure 3a) or mandatory access provisions (Figure 3b) were adopted, which further adds a degree of confidence that trends in 
outcomes are not driving the adoption of these laws. Mandatory access provisions (Figure 3b) have a much larger impact than PDMPs (Figure 3a) without such provisions, although the latter may have an effect on the 18-24 age group. Where there are effects, they only appear to materialize after the adoption of the law, which is validating. The event study also underscores important dynamics in the policy response. Strongest impact of mandatory PDMPs materializes about two years post enactment, which we use to estimate the standard DD effects reported below. This dynamic possibly reflects lags in the diffusion of provider practice (as it may take time for providers to change their practice styles and start querying the PDMP even after mandatory provisions are enacted) and/or lags between reduced doctor shopping, Rx drug diversion, and constrained access through other supply sources. ${ }^{9}$

\subsection{Main Results}

Table 2 presents the estimated effect of PDMPs on treatment admissions related to Rx drugs, based on equation (2). We find that state-specific trends are a significant source of confounding, which may explain some of the nil effects as well as inconsistencies in the previous literature. Consistent with Buchmueller and Carey (2017), we do not find any evidence that an operational PDMP significantly affects treatment admissions related to Rx drug abuse, but there is strong evidence that, conditional on having an operational PDMP, mandatory-access provisions have a significant negative effect. Notably the estimated impact of mandatory access provisions in the full sample controlling for PDMPs is similar to the estimated effect on the subsample of states having a PDMP. This provides reassurance that our estimation strategy is able to control effectively for differences in trends across PDMP adopting and non-adopting states and that our estimates bear a causal interpretation.

\footnotetext{
${ }^{9}$ Lagged effects are also plausible if Rx drug abusers have stockpiled supplies or are able to turn to other supply sources in the short run.
} 
The magnitude of the effect is economically significant. We find that the adoption of mandatory access provisions is associated with about 5.8 fewer treatment admissions per 10,000 individuals ages $18-24$, a $32 \%$ decrease relative to the sample mean for adopting states in the year prior to the year of impact. We also find evidence of about 3.2 fewer admissions among persons $25-44$ years of age, a 17\% decrease, and 0.34 fewer admissions among older (45+) adults, a $12 \%$ decrease. For instance, data from the NSDUH suggest that young adults ages $18-25$ are the biggest abusers of opioids, ADHD stimulants and anti-anxiety medications. ${ }^{10}$ On the other hand, Han et al. (2015) report that the population accessing opioid treatment is growing older, and by 2012 the largest age group represented in New York State opioid treatment programs were older adults ages $50-59 .{ }^{11}$

Subsequent investigations by subcategory of Rx drug abuse, reported in Table 3, suggest that most of the effect is driven by opioid abuse. The effect on treatment admissions for benzodiazepine and stimulants abuse is small and statistically insignificant.

In addition to the direct effect on prescription drug abuse, PDMPs could have spillovers into related markets. Heroin, a pharmacologic substitute for opioids is a good candidate. However, it is not ex ante obvious that a decrease in opioid use would translate into a substitution toward heroin because a reduction in abuse could reduce the total pool of abusers choosing among various types of substances. The estimates reported in Table 4, for heroin abuse, are not statistically significant. On the other hand, we find evidence of a decrease in treatment admissions related to cocaine abuse, consistent with the complementarity between opioids and

\footnotetext{
10 http://www.drugabuse.gov/related-topics/trends-statistics/infographics/abuse-prescription-rx-drugs-affectsyoung-adults-most accessed 1/8/2015.

${ }^{11}$ While we also present estimates for adolescents, we do not expect that PDMPs, which are targeted at curbing doctor shopping, would have any substantial effect for this age group, and indeed generally find no significant effects on admissions among individuals ages 12-17.
} 
cocaine indicated in the literature. There is also some evidence of a negative association between mandatory PDMPs and treatment admissions due to marijuana abuse, suggestive of complementarity between opioids and marijuana, although the estimates are only marginally significant (at the $10 \%$ significance level). ${ }^{12}$

\subsection{Validity Checks}

One way to assess whether our estimates reflect the impact of mandatory PDMPs or are capturing some other confounding factor is to investigate the mechanism of the effect. If the mandatory-access provisions of PDMPs are driving the effect, then the source of the increase in admissions should mostly reflect either referrals by physicians that caught on to their patients' illicit behavior or self-referral by individuals that lost access to prescription drugs, or referrals from the abusers' immediate kith or kin noticing behavioral changes. Because the outside community does not have access to PDMPs, school or workplace referrals should not change except perhaps as a secondary effect of the reduced Rx abuse. Similarly, because voluntary PDMPs predate mandatory-access PDMPs, the criminal justice system already had access to this information. Therefore, any changes in referrals by courts and the criminal justice system also reflect second-order effects and are, thus, expected to be much smaller than changes in selfreferrals or physician referrals.

In order to assess these mechanisms, we split the data by source of referral. ${ }^{13}$ One group identifies admissions most likely to be impacted by mandatory-access PDMPs; these include individual referrals (self-referrals and those from family/friends) and referrals by substance

\footnotetext{
${ }^{12}$ We also find that PDMPs are negatively associated with treatment admissions for alcohol abuse, and positively associated with admissions for abuse related to over-the-counter medication, although none of these is significant at conventional levels (see Appendix Tables A2 and A3).

${ }^{13}$ The source of referral has missing values. For this analysis, we drop all cells with more than $10 \%$ missing values for the source of referral.
} 
abuse care or other healthcare providers. The second group isolates treatment admissions from school, employer, and other community referrals, and court/criminal justice referrals. We report these estimated effects of PDMPs by source of referral in Table 5. As expected, most of the estimated effect is driven by changes in referrals from individuals and physicians, providing further support, our estimates are in fact identifying the effect of mandatory PDMPs. Effects for other types of referrals, which are not expected to be shifted by mandatory PDMP provisions or which may only reflect second-order effects, are statistically insignificant and much smaller in magnitude.

In another related validity check implied by the mechanisms underlying any potential policy effect, we examine differential effects across urbanicity. As prescription drug abuse is more prevalent in rural areas (National Drug Intelligence NDIC 2004; Wang et al. 2013), if our estimates reflect unmeasured trends we should observe a larger effect in rural areas. On the other hand, PDMPs target individuals that attempt to obtain prescriptions from several physicians. Due to transportation costs, this is easier to do in urban areas. By 2007, when the mandatory PDMPs started being adopted, 37 states including all but one ${ }^{14}$ that adopted mandatory PDMPs, had already passed laws requiring physicians to meet their patients in person prior to prescribing controlled substances (PER laws). Thus, travel time is a significant deterrent to a person living in rural areas attempting to obtain prescriptions from multiple providers. If the estimates are capturing a causal effect of PDMPs, it is plausible that the effect is likely to be concentrated in urban areas. Table 6 reports estimates for admissions by metropolitan location. It is validating that the decrease in treatment admissions among adults is concentrated in metropolitan areas with virtually no effect in rural areas.

\footnotetext{
${ }^{14}$ Delaware adopted mandatory PDMP in 2010 and the physical examination requirement in 2012.
} 


\subsection{Robustness Checks}

Finally, we confirmed that our results are not sensitive to alternate functional forms or model specifications that, alternately: 1) accounted for cross-border effects by controlling for PDMP status of neighboring states; 2) excluded all cells with zero admissions; 3) estimated unweighted specifications; and 4) specified the outcome as the natural log of the rate or the natural $\log$ of the odds ratio. ${ }^{15}$

\section{CONCLUSION}

This study contributes to the literature on the effects of laws targeting prescription drug abuse. Focusing on treatment admissions for prescription drug abuse, we find that mandatory PDMPs are effective in reducing the use of medical care to address prescription drug misuse. Treatment admissions are an arguably better measure of the impact of these policies than sales of prescription drugs, the focus of previous research. A reduction in sales due to fewer prescriptions filled could conceivably reduce illicit access to prescription drugs. However, it could also lead to an increase in the price on the black market, thus, providing incentives for private individuals to sell their legitimate prescriptions. When prescription beneficiaries reduce their own consumption but do not reduce diversion to others, a reduction in sales may not imply reduced abuse and could affect outcomes negatively. Diversion is more closely related to abuse and negative health outcomes and, thus, increased use of medical care to treat addiction or abuse.

In addition, we find evidence of significant spillovers to the markets of illegal drugs: mandatory access PDMPs are associated with reduction in treatment admissions for abuse of

\footnotetext{
${ }^{15}$ For brevity, we report a subset of these checks in Appendix Table A1. All other estimates are available upon request.
} 
cocaine and marijuana, both known opioids' complements in consumption. Taken together these results provide suggestive evidence that mandatory PDMPs are effective in addressing drug diversion. Our estimates also highlight a possible reason for the inconsistency and limited effects uncovered in the prior literature, as most of the literature had not differentiated between voluntary-access and mandatory-access PDMPs. Having an operational PDMP is not sufficient; it is important that providers query the PDMP prior to prescribing and dispensing. Given the low PDMP utilization rates where PDMP access is voluntary, mandating access prior to prescribing and dispensing a controlled substance can be effective in reducing abuse related to Rx drugs and complementary substances.

The results are robust to a significant range of stress tests and are suggestive of a causal interpretation. Analyses with the TEDS data also makes it feasible to estimate the policy effect while allowing for differences in trends across different age groups. We found that failure to control for trends in utilization leads to biased estimates. Because the cause of misuse varies widely by age, it is likely that these trends would also vary by age. Failure to account for differences in trends across age groups may be another reason for limited effects and inconsistent findings in the previous literature. 


\section{References}

Ali, Mir M., William N. Dowd, Timothy Classen, Ryan Mutter, and Scott P. Novak. 2017. "Prescription drug monitoring programs, nonmedical use of prescription drugs, and heroin use: Evidence from the National Survey of Drug Use and Health." Addictive Behaviors 69: $65-77$

Alexander GC, Frattaroli S, Gielen AC, eds. The Prescription Opioid Epidemic: An EvidenceBased Approach. Johns Hopkins Bloomberg School of Public Health, Baltimore, Maryland, 2015

Angrist, Joshua D., and Jörn-Steffen Pischke. Mostly Harmless Econometrics: An Empiricist's Companion. Princeton University Press, 2009.

Bachhuber, Marcus A., Brendan Saloner, Chinazo O. Cunningham. 2014. "Medical Cannabis Laws and Opioid Analgesic Overdose Mortality in the United States, 1999-2010." JAMA Internal Med. 174(10): 1668-1673

Bertrand, Marianne, Esther Duflo and Sedhil Mullainathan. 2004. "How much Should We Trust Differences-in-Differences Estimates?" The Quarterly Journal of Economics 119(1): 249-275.

Brady, J.E., Wunsch, H., DiMaggio, C., Lang, B.H., Giglio, J. and Li, G., 2014. Prescription drug monitoring and dispensing of prescription opioids. Public Health Reports, 129(2), pp.139-147.

Buchmueller, Thomas C. and Coleen Carey. 2017. "The Effect of Prescription Drug Monitoring Programs on Opioid Utilization in Medicare" NBER working paper No. 23149

Case, Anne and Angus Deaton. 2015. "Rising morbidity and mortality in midlife among white non-Hispanic Americans in the $21^{\text {st }}$ century," in Proceedings of the National Academy of the Sciences of the United States of America 112(49): 15078-15083

Clemow, David B. and Daniel J. Walker. 2014. The Potential for Misuse and Abuse of Medications in ADHD: A Review, Postgraduate Medicine Vol. 126, Iss. 5

Dave, Dhaval, and S. Mukerjee.2011. "Mental Health Parity Legislation, Cost-Sharing, and Substance-Abuse Treatment Admissions." Health Economics 20: 161-183.

Finklea, Kristin; Sacco, Lisa N; Bagalman, Erin. 2014.Journal of Drug Addiction, Education, and Eradication; Hauppauge10.4: 481-505.

Florence CS, Zhou C, Luo F, and Xu L.2016). "The Economic Burden of Prescription Opioid Overdose, Abuse, and Dependence in the United States, 2013." Medical Care 54(10): 901906.

Haegerich, Tamara M., Leonard J. Paulozzi, Brian J. Manns, and Christopher M. Jones. 
2014."What we know, and don't know, about the impact of state policy and systems-level interventions on prescription drug overdose." Drug and Alcohol Dependence 145: $34-47$

Haffajee RL, Jena AB, and Weiner SC. 2015. "Mandatory Use of Prescription Drug Monitoring Programs." Journal of the American Medical Association 313(9): 891-892.

Han Benjamin, Soteri Polydorou, Rosie Ferris, Caroline S. Blaum, Stephen Ross and Jennifer McNeely. 2015. "Demographic Trends of Adults in New York City Opioid Treatment Programs-An Aging Population." Substance Use \& Misuse 50(13): 1660-1667.

Inciardi J, Surratt H, Cicero T, and Beard R. 2009. "Prescription Opioid Abuse and Diversion in an Urban Community: The Results from an Ultra-Rapid Assessment." Pain Medicine 10(3): 537-548.

Jena, Anupam B., Dana Goldman, Lesley Weaver, and Pinar Karaca-Mandic, 2014. "Opioid Prescribing By Multiple Providers in Medicare: Retrospective Observational Study of Insurance Claims," British Medical Journal, 348.

Jones C, Paulozzi L, and Mack K. 2014. "Sources of Prescription Opioid Pain Relievers by Frequency of Past-Year Medical Use United States 2008-2011." Journal of the American Medical Association 174(5): 802-803.

Lipari RN and Hughes A. 2015. "Trends in Heroin Use in the United States." The CBHSQ Report, Substance Abuse and Mental Health Services Administration, April 23, 2015.

Manchikanti L, Singh V, Caraway DL, and Benyamin RM. 2011. "Breakthrough Pain in Chronic Non-Cancer Pain: Fact, Fiction, or Abuse." Pain Physician 14(2): E103-117.

Manchikanti L, Fellows B, Ailinani H, and Pampati V. 2010. "Therapeutic Use, Abuse, and Non-Medical Use of Opioids: A Ten-year Perspective.” Pain Physician 13(5): 401-435.

Maxwell, Jane Carlisle. 2006. "Trends in the Abuse of Prescription Drugs." The Center for Excellence in Drug Epidemiology, The Gulf Coast Addiction Technology Transfer Center The University of Texas at Austin.

McCall Jones, Christopher, Grant T. Baldwin, Wilson M. Compton. 2017. "Recent Increases in Cocaine-Related Overdose Deaths and the Role of Opioids." American Journal of Public Health 107(3): 430-432.

McDonald, Douglas C., Kenneth Carlson and David Izrael. 2012. "Geographic variation in opioid prescribing in the US." The Journal of Pain 13(10): 988-996.

Meara, Ellen, Jill R. Horwitz, Wilson Powell, Lynn McClelland, Weiping Zhou, A. James O'Malley, and Nancy E. Morden. 2016. "State Legal Restrictions and Prescription-Opioid Use among Disabled Adults." New England Journal of Medicine 375(1): 44-53. 
National Center on Addiction and Substance Abuse. 2005. Under the Counter: The Diversion and Abuse of Controlled Prescription Drugs in the U.S., Columbia University, New York

National Drug Intelligence Center. 2004. Intelligence Bulletin: OxyContin Diversion, Availability, and Abuse, Document ID: 2004-L0424-017, available at: http://www.justice.gov/archive/ndic/pubs10/10550/index.htm, accessed on May, 24, 2017

National Survey on Drug Use and Health. 2016. "Prescription Drug Use and Misuse in the United States: Results from the 2015 National Survey on Drug Use and Health." NSDUH Data Review, Substance Abuse and Mental Health Services Administration September.

Nedeljkovic S. S., Wasan A., \& Jamison, R.N. 2002. "Assessment of efficacy of long-term opioid therapy in pain patients with substance abuse potential." The Clinical Journal of Pain, 18(4): S39-S51.

Paulozzi, Leonard J., Edwin M. Kilbourne, and Hema A. Desai. 2011. "Prescription Drug Monitoring Programs and Death Rates from Drug Overdose." Pain Medicine 12(5): 747-754.

Radakrishnan, Sharmini. 2014. "The impact of information in health care markets: prescription drug monitoring programs and abuse of opioid pain relievers."

Downloaded from http://paa2014.princeton.edu/papers/143182 on 5/22/2017

Reisman, Richard M., Pareen J. Pareen J. Shenoy, Adam J. Atherly, and Christopher R. Flowers. 2009. Prescription opioid usage and abuse relationships: an evaluation of state prescription drug monitoring program efficacy. Substance Abuse: Research and Treatment 3: 41-51

Rudd RA, Seth P, David F, Scholl L. 2016. "Increases in Drug and Opioid-Involved Overdose Deaths — United States, 2010-2015." Morbidity and Mortality Weekly Report 65(50-51): 1445-1452.

Shatter Proof. 2016. "Prescription Drug Monitoring Programs: Critical Elements of Effective State Legislation." https://www.shatterproof.org/advocacy/state-by-stateinformation/Prescription-Drug-Monitoring-Programs, Accessed 3/1/2017.

Simeone, Roland and Lynn Holland. 2006. "An Evaluation of Prescription Drug Monitoring Programs.” Available at http://www.simeoneassociates.com/simeone3.pdf. Accessed October 4, 2015

Teter, C.J., McCabe, S.E., Cranford, J.A., Boyd, C.J. and Guthrie, S.K., 2005. Prevalence and motives for illicit use of prescription stimulants in an undergraduate student sample. Journal of American College Health, 53(6), pp.253-262.

Torabi, Mohammad R., William J. Bailey, Massoumeh Majd-Jabbari. 2003. "Cigarette Smoking as a Predictor of Alcohol and Other Drug use by Children and Adolescents: Evidence of the “Gateway Drug Effect." Journal of School Health 63(7), 302-6. 
Wang K.H., Becker W.C., Fiellin D.A. 2013 "Prevalence and correlates for nonmedical use of prescription opioids among urban and rural residents." Drug Alcohol Dependence 127(1-3): $156-62$

Wood, M.D., Read, J.P., Palfai, T.P., \& Stevenson, J.F. 2001. "Social influence processes and college student drinking: The meditational role of alcohol outcome expectancies." Journal of Studies on Alcohol, 62, 32-43.

Worley, Julie. 2012. "Prescription Drug Monitoring Programs, a Response to Doctor Shopping: Purpose, Effectiveness, and Directions for Future Research." Issues in Mental Health Nursing 33(5), 319-328. 
Figure 1a. Legislative status of PDMPs during the 2003-2014 period

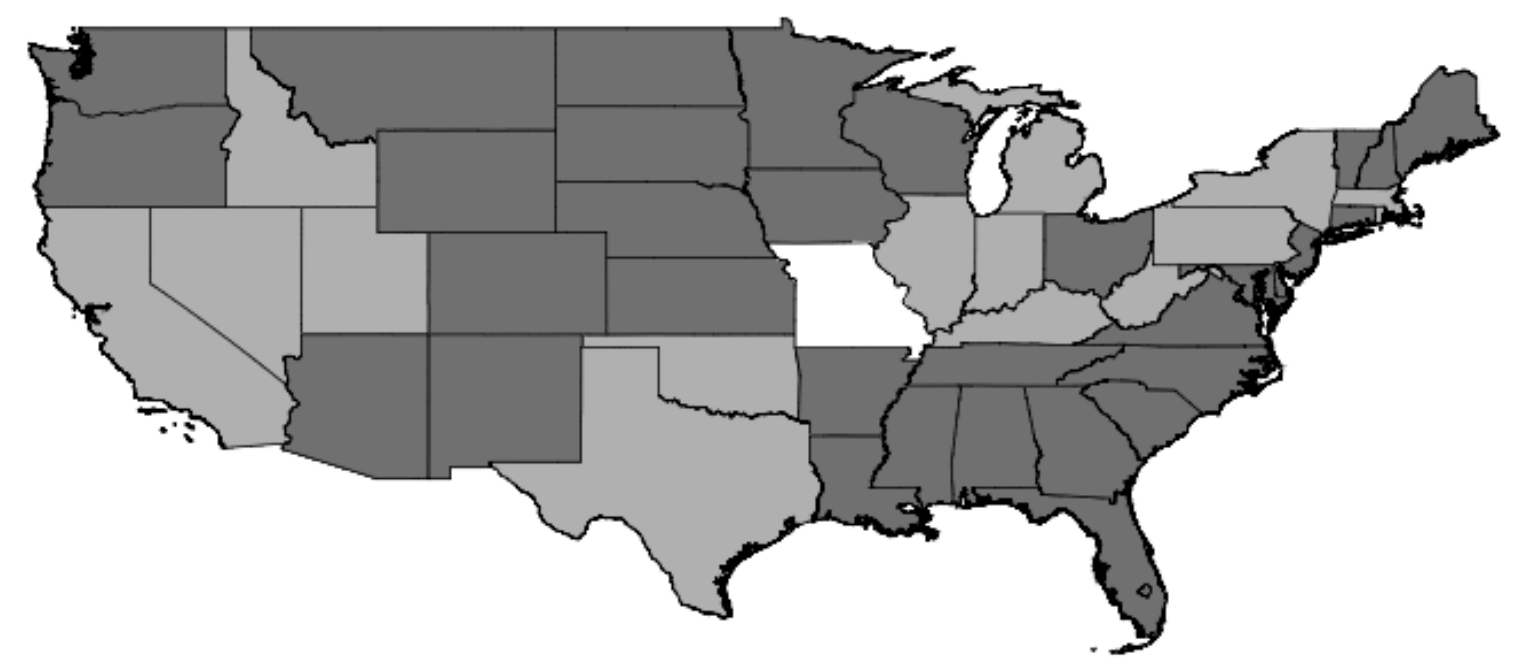

White areas do not have a PDMP, light grey shaded areas had an operational PDMP before 2003, dark grey shaded areas identify states where PDMPs became operational during the 2003-2014 period.

Figure 1b. Adoptions of Mandatory Access PDMPs 2003-2014

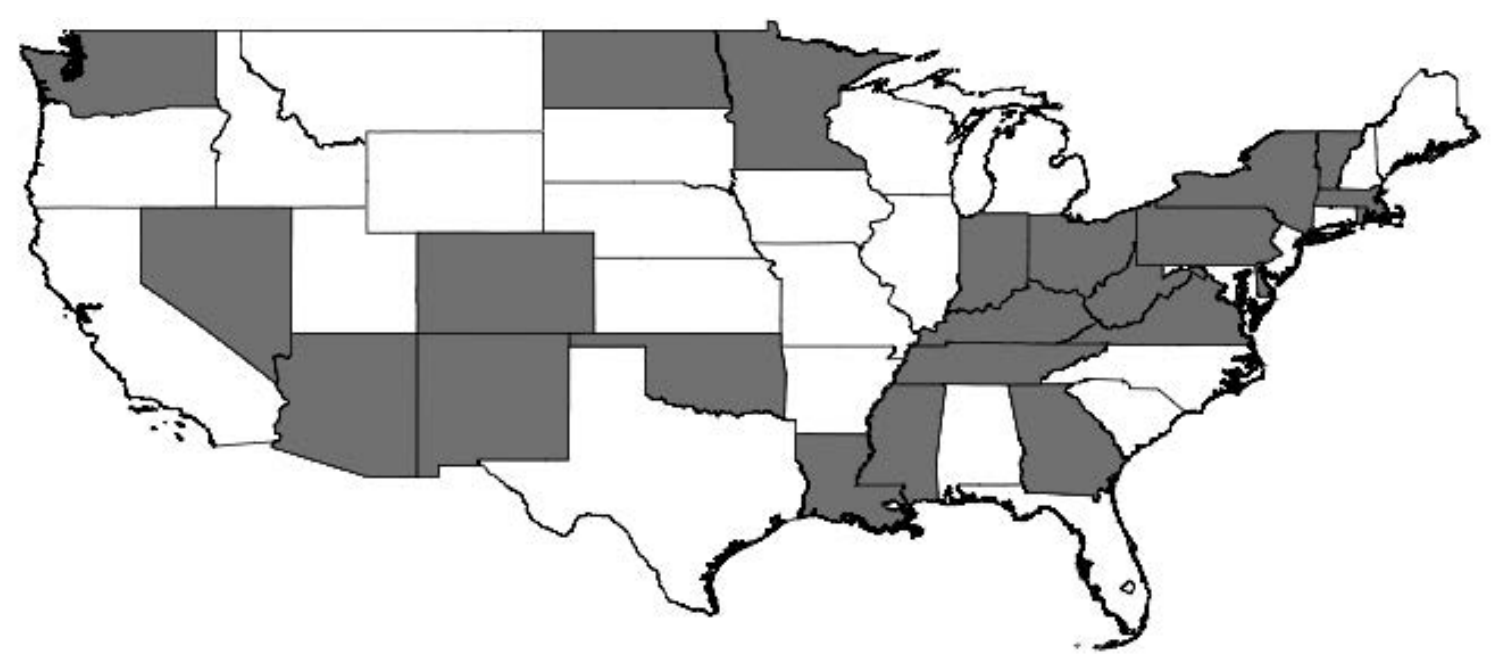

Shaded areas identify states that adopted mandatory access provisions before 2014 Source: National Alliance for Model State Drug Laws. 
Figure 2. Treatment admissions for prescription drug misuse

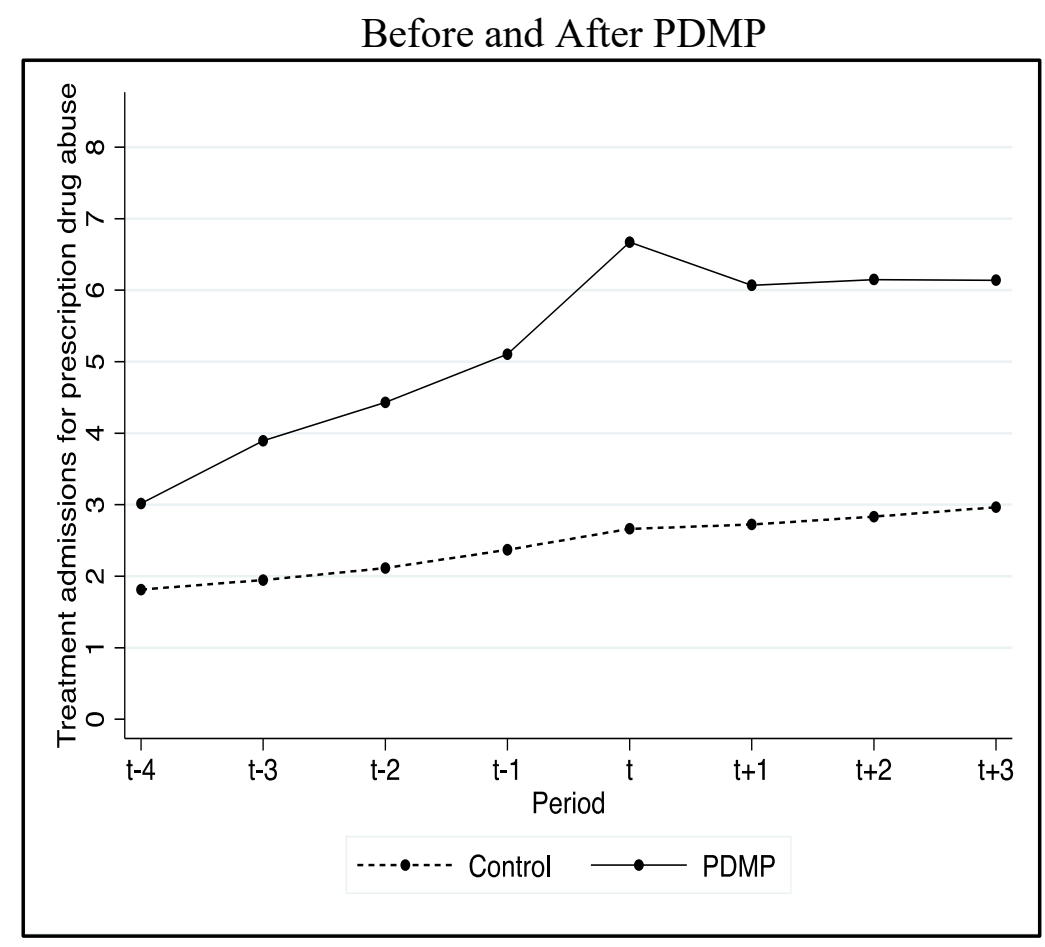

The control group is all state-years with no PDMP.

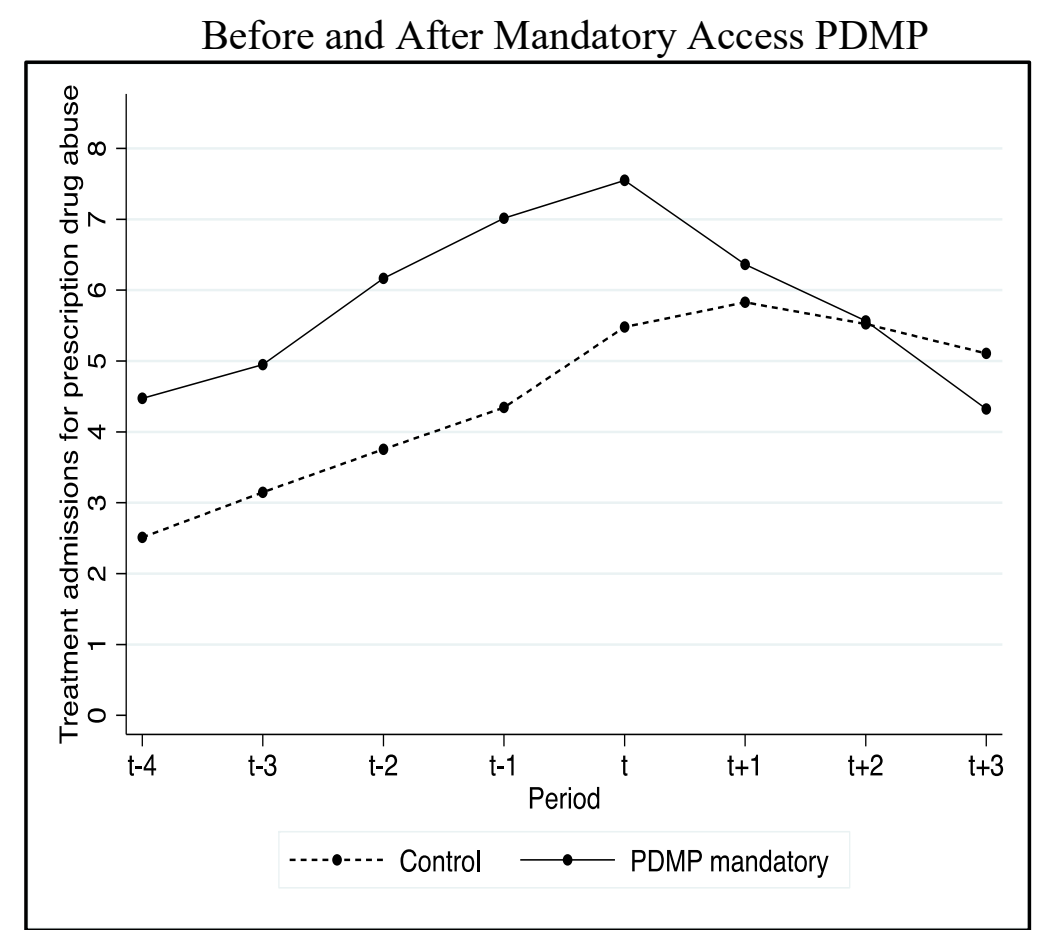

The control group is all state-years with PDMP but no mandatory access provisions.

Note: For the purpose of these graphs, we retained only states that passed legislation before 2012 so that we avoid significant changes in sample when obtaining the means 2 and 3 years after the legislative change. 
Figure 3a. Estimated impact of PDMP on treatment admissions for years before, during and after adoption. All Drugs
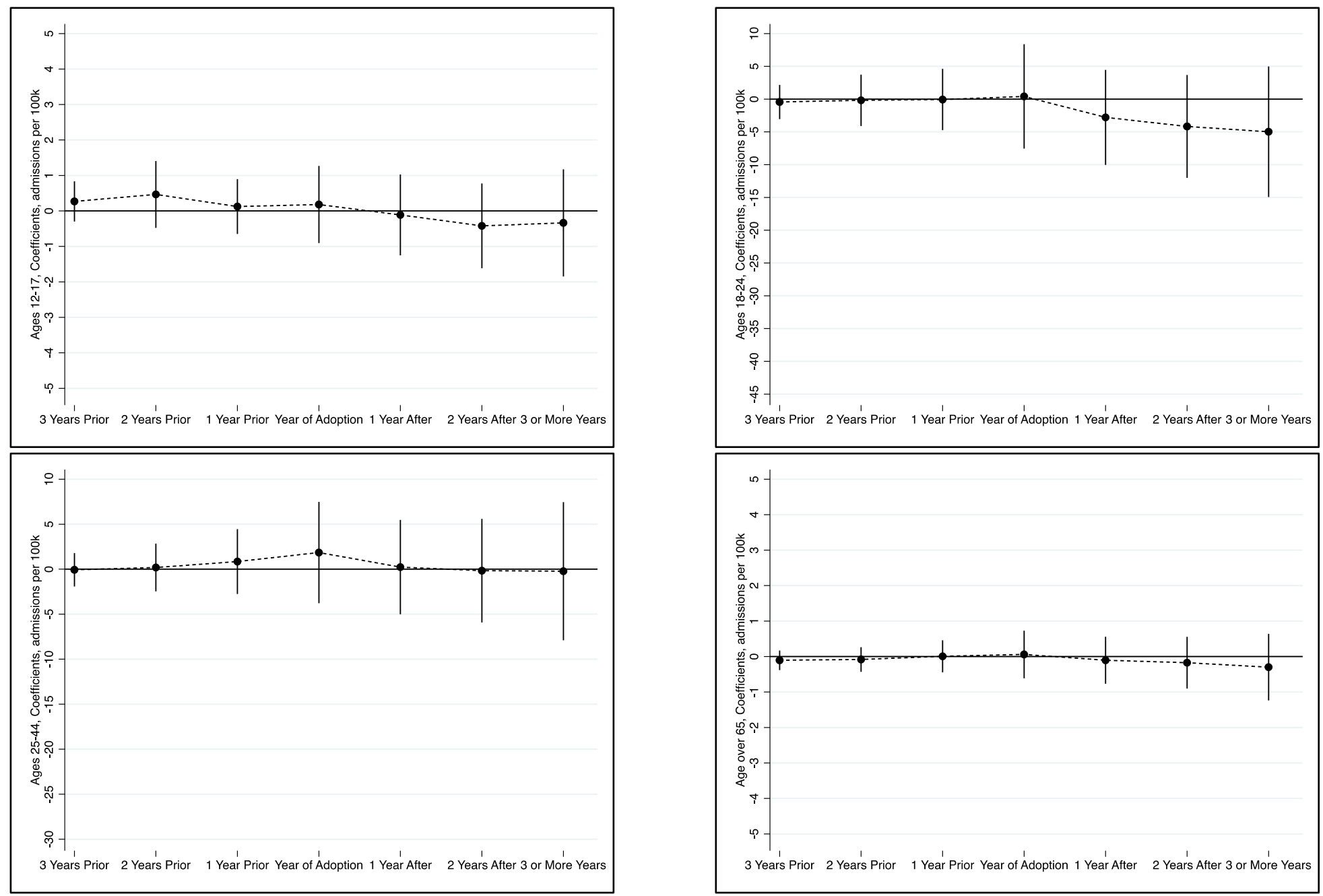

Vertical bands represent $95 \%$ confidence intervals around each point estimate. The vertical scale was chosen to allow comparisons of figure $3 \mathrm{a}$ and $3 \mathrm{~b}$. 
Figure 3b. Estimated impact of mandatory access PDMP on treatment admissions for years before, during and after adoption. The control group is all state-years with an operational PDMP but no mandatory access provisions. All Drugs
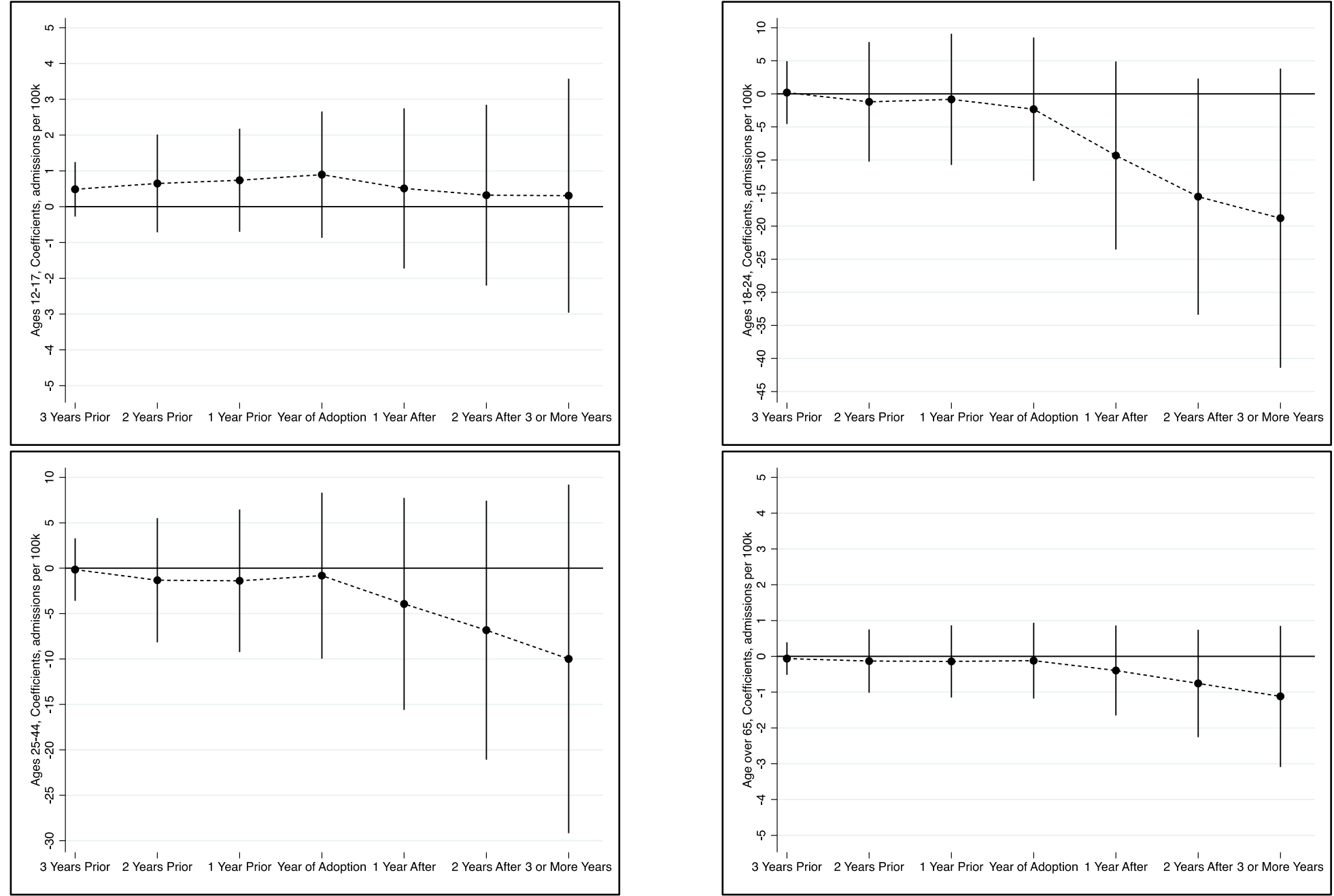

Vertical bands represent $95 \%$ confidence intervals around each point estimate. The vertical scale was chosen to allow comparisons of figures $3 \mathrm{a}$ and $3 \mathrm{~b}$. 
Table 1. Summary Statistics

\begin{tabular}{|c|c|c|c|c|c|}
\hline & \multicolumn{2}{|c|}{ No PDMP } & \multicolumn{2}{|c|}{ PDMP } & \multirow[b]{2}{*}{ t-statistic } \\
\hline & mean & $\mathrm{sd}$ & mean & sd & \\
\hline Treatment admissions & 4.266 & 3.131 & 6.642 & 4.58 & 0.596 \\
\hline Male & 48.817 & 0.635 & 48.771 & 0.69 & -1.446 \\
\hline Black & 14.571 & 10.335 & 14.776 & 10.193 & -0.572 \\
\hline Other Race & 4.179 & 2.584 & 4.499 & 3.046 & -0.069 \\
\hline Age 18-24 & 11.648 & 0.957 & 11.586 & 0.831 & -1.645 \\
\hline Age $25-44$ & 32.691 & 2.036 & 31.616 & 1.811 & 0.644 \\
\hline Age $\geq 45$ & 45.763 & 2.736 & 47.128 & 2.673 & 0.213 \\
\hline Unemployment Rate & 5.757 & 1.791 & 7.144 & 2.601 & 0.801 \\
\hline Income per capita & 18447.2 & 2784.9 & 18205.0 & 2769.9 & -0.872 \\
\hline Medicaid & 7.11 & 1.949 & 8.445 & 1.705 & 0.811 \\
\hline Medicare & 18.729 & 2.918 & 19.168 & 2.785 & 0.582 \\
\hline \multirow[t]{3}{*}{ Physicians } & 53.393 & 14.394 & 52.499 & 9.916 & -0.637 \\
\hline & \multicolumn{2}{|c|}{$\begin{array}{c}\text { PDMP } \\
\text { No Mandatory Access }\end{array}$} & \multicolumn{2}{|c|}{$\begin{array}{c}\text { PDMP } \\
\text { Mandatory Access }\end{array}$} & \\
\hline & mean & $\mathrm{sd}$ & mean & $\mathrm{sd}$ & t-statistic \\
\hline Treatment admissions & 5.068 & 4.413 & 7.091 & 5.979 & 1.296 \\
\hline Male & 48.941 & 0.661 & 48.768 & 0.641 & 1.081 \\
\hline Black & 12.076 & 6.384 & 14.105 & 7.989 & 1.503 \\
\hline Other Race & 7.221 & 7.049 & 5.855 & 3.072 & -0.424 \\
\hline Age 18-24 & 12.017 & 0.849 & 11.777 & 0.611 & 0.501 \\
\hline Age $25-44$ & 32.773 & 2.244 & 31.378 & 1.836 & 0.174 \\
\hline Age $\geq 45$ & 45.197 & 3.441 & 47.338 & 2.623 & -0.898 \\
\hline Unemployment Rate & 7.126 & 2.298 & 7.585 & 1.53 & 1.287 \\
\hline Income per capita & 18811.3 & 2400.1 & 19325.9 & 3126.2 & $-1.902 *$ \\
\hline Medicaid & 9.166 & 2.836 & 10.118 & 3.301 & -1.264 \\
\hline Medicare & 18.311 & 2.679 & 19.442 & 2.464 & -1.104 \\
\hline Physicians & 54.373 & 11.926 & 56.567 & 14.886 & $1.690^{*}$ \\
\hline
\end{tabular}

Mean and standard deviation (sd) are reported. T-statistic reports statistical significance for the difference in the sample means between the two groups. $* * * \mathrm{p}<0.01, * * \mathrm{p}<0.05, * \mathrm{p}<0.1$ 
Table 2. The impact of mandatory PDMPs on treatment admissions for prescription drug abuse

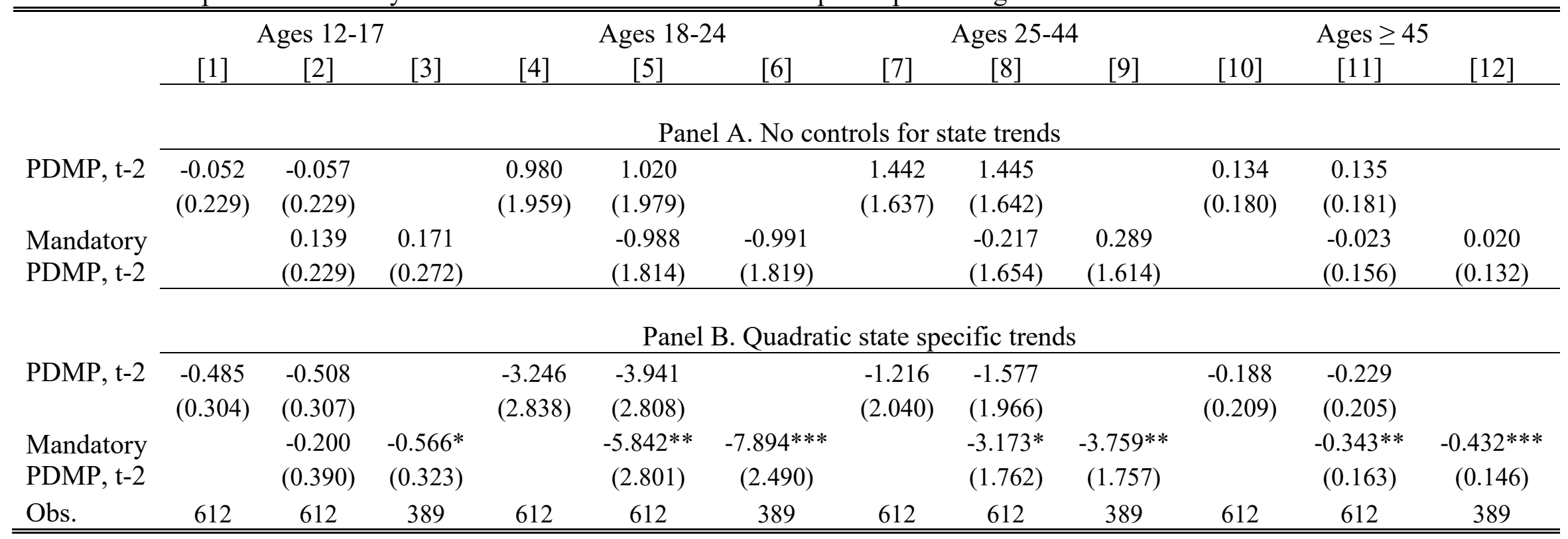

Regressions reported in columns 3,6, and 9 retain only the sample of state-years with an operational PDMP. The drugs considered in panel A are opiates and synthetics, stimulants, benzodiazepines, non-benzodiazepine tranquilizers, barbiturates, and inhalants. All regressions use 2003-2014 data. All regressions control for percent male, percent black, percent other race in age group and state age structure of population: age 12-17 (omitted), age 18-24, age 25-44, age over 45), state unemployment rate, per capita income, percent of population over 18 covered by Medicaid, percent of population over 18 covered by Medicare, number of physicians per 10,000 people, ID laws and Physical Examination Requirement laws. All regressions control for state and year fixed effects. All regressions are weighted by the population in the relevant age group. Robust standard errors clustered at state level are reported in parentheses.

$* * * \mathrm{p}<0.01, * * \mathrm{p}<0.05, * \mathrm{p}<0.1$ 
Table 3. The impact of PDMPs on treatment admissions for abuse of Rx drugs by type

\begin{tabular}{|c|c|c|c|c|}
\hline & Ages $12-17$ & Ages 18-24 & Ages 25-44 & Ages $\geq 45$ \\
\hline & \multicolumn{4}{|c|}{ Panel A. Opioids } \\
\hline \multirow[t]{2}{*}{ PDMP, $\mathrm{t}-2$} & $-0.400 *$ & -3.901 & -1.630 & -0.217 \\
\hline & $(0.231)$ & $(2.577)$ & $(1.777)$ & $(0.159)$ \\
\hline \multirow[t]{2}{*}{ Mandatory PDMP, t-2 } & -0.302 & $-5.584 * *$ & $-3.007 *$ & $-0.371 * *$ \\
\hline & $(0.287)$ & $(2.739)$ & $(1.625)$ & $(0.151)$ \\
\hline \multirow[t]{2}{*}{ Obs. } & 612 & 612 & 612 & 612 \\
\hline & \multicolumn{4}{|c|}{ Panel B. Benzodiazepines } \\
\hline \multirow[t]{2}{*}{ PDMP, $\mathrm{t}-2$} & -0.118 & -0.192 & -0.057 & -0.016 \\
\hline & $(0.086)$ & $(0.190)$ & $(0.149)$ & $(0.032)$ \\
\hline \multirow[t]{2}{*}{ Mandatory PDMP, t-2 } & -0.020 & -0.249 & -0.161 & -0.058 \\
\hline & $(0.070)$ & $(0.200)$ & $(0.143)$ & $(0.041)$ \\
\hline \multirow[t]{2}{*}{ Obs. } & 612 & 612 & 612 & 612 \\
\hline & \multicolumn{4}{|c|}{ Panel C. Stimulants } \\
\hline \multirow[t]{2}{*}{ PDMP, t-2 } & 0.083 & $0.026^{*}$ & 0.015 & -0.002 \\
\hline & $(0.082)$ & $(0.015)$ & $(0.013)$ & $(0.004)$ \\
\hline \multirow[t]{2}{*}{ Mandatory PDMP, $\mathrm{t}-2$} & 0.071 & -0.002 & -0.010 & 0.001 \\
\hline & $(0.076)$ & $(0.028)$ & $(0.022)$ & $(0.005)$ \\
\hline Obs. & 612 & 612 & 612 & 612 \\
\hline
\end{tabular}

All regressions use 2003-2014 data. All regressions control for percent male, percent black, percent other race in age group and state age structure of population: age 12-17 (omitted), age 18-24, age 25-44, age over 45), state unemployment rate, per capita income, percent of population over 18 covered by Medicaid, percent of population over 18 covered by Medicare, number of physicians per 10,000 people, ID laws and Physical Examination Requirement laws. All regressions control for state and year fixed effects, and quadratic state specific trends. All regressions are weighted by the population in the relevant age group. Robust standard errors clustered at state level are reported in parentheses.

$* * * \mathrm{p}<0.01,{ }^{* *} \mathrm{p}<0.05,{ }^{*} \mathrm{p}<0.1$ 
Table 4. The impact of PDMPs on treatment admissions for abuse of illicit drugs

\begin{tabular}{lcccc}
\hline \hline & Ages 12-17 & Ages 18-24 & Ages 25-44 & Ages $\geq 45$ \\
\cline { 2 - 5 } PDMP, t-2 & \multicolumn{4}{c}{ Panel A. Heroin } \\
\cline { 2 - 5 } & $(0.013$ & 0.588 & 1.720 & -0.064 \\
Mandatory PDMP, t-2 & 0.064 & $(2.003)$ & $(1.401)$ & $(0.322)$ \\
& $(0.200)$ & -0.108 & 2.367 & -0.009 \\
Obs. & 612 & $6.386)$ & $(3.425)$ & $(0.471)$ \\
& \multicolumn{4}{c}{ Panel B. Cocaine } \\
PDMP, t-2 & -0.038 & -0.389 & -0.717 & 0.072 \\
& $(0.113)$ & $(0.589)$ & $(1.477)$ & $(0.422)$ \\
Mandatory PDMP, t-2 & 0.005 & $-0.933^{*} *$ & $-2.387 * *$ & $-1.180^{* *}$ \\
& $(0.073)$ & $(0.459)$ & $(1.041)$ & $(0.560)$ \\
Obs. & 612 & 612 & 612 & 612 \\
\hline & \multicolumn{4}{c}{ Panel C. Marijuana } \\
PDMP, t-2 & $-9.970^{*}$ & -1.537 & 0.635 & 0.054 \\
& $(5.119)$ & $(3.757)$ & $(1.646)$ & $(0.157)$ \\
Mandatory PDMP, t-2 & -3.360 & $-8.235^{*}$ & $-3.344 *$ & -0.276 \\
& $(6.011)$ & $(4.891)$ & $(1.826)$ & $(0.168)$ \\
Obs. & 612 & 612 & 612 & 612 \\
\hline \hline
\end{tabular}

All regressions use 2003-2014 data. All regressions control for percent male, percent black, percent other race in age group and state age structure of population: age 12-17 (omitted), age 18-24, age 25-44, age over 45), state unemployment rate, per capita income, percent of population over 18 covered by Medicaid, percent of population over 18 covered by Medicare, number of physicians per 10,000 people, ID laws and Physical Examination Requirement laws. All regressions control for state and year fixed effects, and quadratic state specific trends. All regressions are weighted by the population in the relevant age group. Robust standard errors clustered at state level are reported in parentheses.

$* * * \mathrm{p}<0.01, * * \mathrm{p}<0.05, * \mathrm{p}<0.1$ 
Table 5. The impact of PDMPs on treatment admissions for prescription drug abuse by source of referral

\begin{tabular}{|c|c|c|c|c|c|c|c|c|}
\hline & \multicolumn{2}{|c|}{ Ages 12-17 } & \multicolumn{2}{|c|}{ Ages 18-24 } & \multicolumn{2}{|c|}{ Ages 25-44 } & \multicolumn{2}{|c|}{ Ages $\geq 45$} \\
\hline & $\begin{array}{c}\text { Self or } \\
\text { Physician }\end{array}$ & $\begin{array}{c}\text { Courts or } \\
\text { Community }\end{array}$ & $\begin{array}{c}\text { Self or } \\
\text { Physician }\end{array}$ & $\begin{array}{c}\text { Courts or } \\
\text { Community }\end{array}$ & $\begin{array}{c}\text { Self or } \\
\text { Physician }\end{array}$ & $\begin{array}{c}\text { Courts or } \\
\text { Community }\end{array}$ & $\begin{array}{c}\text { Self or } \\
\text { Physician }\end{array}$ & $\begin{array}{c}\text { Courts or } \\
\text { Community }\end{array}$ \\
\hline PDMP, $\mathrm{t}-2$ & $\begin{array}{l}-0.190 \\
(0.165)\end{array}$ & $\begin{array}{l}-0.301 * \\
(0.172)\end{array}$ & $\begin{array}{l}-2.194 \\
(2.239)\end{array}$ & $\begin{array}{l}-1.536 \\
(1.174)\end{array}$ & $\begin{array}{l}-1.098 \\
(1.327)\end{array}$ & $\begin{array}{l}-0.627 \\
(0.744)\end{array}$ & $\begin{array}{l}-0.174 \\
(0.160)\end{array}$ & $\begin{array}{l}-0.078 \\
(0.061)\end{array}$ \\
\hline Mandatory PDMP, $\mathrm{t}-2$ & $\begin{array}{c}-0.276 \\
(0.198)\end{array}$ & $\begin{array}{c}-0.169 \\
(0.203)\end{array}$ & $\begin{array}{l}-4.011 * \\
(2.123)\end{array}$ & $\begin{array}{l}-1.505 \\
(1.036)\end{array}$ & $\begin{array}{c}-2.486^{* *} \\
(1.084)\end{array}$ & $\begin{array}{c}-0.881 \\
(0.852)\end{array}$ & $\begin{array}{c}-0.270 * * \\
(0.115)\end{array}$ & $\begin{array}{l}-0.115 \\
(0.077)\end{array}$ \\
\hline Obs. & 514 & 514 & 556 & 556 & 554 & 554 & 550 & 550 \\
\hline
\end{tabular}

All regressions use 2003-2014 data. All regressions control for percent male, percent black, percent other race in age group and state age structure of population: age 12-17 (omitted), age 18-24, age 25-44, age over 45), state unemployment rate, per capita income, percent of population over 18 covered by Medicaid, percent of population over 18 covered by Medicare, number of physicians per 10,000 people, ID laws and Physical Examination Requirement laws. All regressions control for state and year fixed effects, and quadratic state specific trends. All regressions are weighted by the population in the relevant age group. Robust standard errors clustered at state level are reported in parentheses.

$* * * \mathrm{p}<0.01, * * \mathrm{p}<0.05, * \mathrm{p}<0.1$ 
Table 6. The impact of PDMPs on treatment admissions for prescription drug abuse by urbanicity

\begin{tabular}{|c|c|c|c|c|c|c|c|c|}
\hline & \multicolumn{2}{|c|}{ Ages $12-17$} & \multicolumn{2}{|c|}{ Ages 18-24 } & \multicolumn{2}{|c|}{ Ages $25-44$} & \multicolumn{2}{|c|}{ Ages $\geq 45$} \\
\hline & Metro & Non-Metro & Metro & Non-Metro & Metro & Non-Metro & Metro & Non-Metro \\
\hline \multirow[t]{2}{*}{ PDMP, $t-2$} & $-0.424 *$ & -0.083 & $-4.419 * *$ & 0.478 & -2.208 & 0.631 & $-0.302 *$ & 0.072 \\
\hline & $(0.219)$ & $(0.130)$ & $(2.098)$ & $(1.028)$ & $(1.402)$ & $(0.730)$ & $(0.154)$ & $(0.075)$ \\
\hline \multirow[t]{2}{*}{ Mandatory PDMP, t-2 } & -0.153 & -0.046 & $-4.882 * *$ & -0.960 & $-2.402 *$ & -0.771 & $-0.270 * *$ & -0.072 \\
\hline & $(0.250)$ & $(0.173)$ & $(2.043)$ & (1.114) & (1.197) & $(0.815)$ & $(0.127)$ & $(0.072)$ \\
\hline Obs. & 612 & 612 & 612 & 612 & 612 & 612 & 612 & 612 \\
\hline
\end{tabular}

All regressions use 2003-2014 data. All regressions control for percent male, percent black, percent other race in age group and state age structure of population: age 12-17 (omitted), age 18-24, age 25-44, age over 45), state unemployment rate, per capita income, percent of population over 18 covered by Medicaid, percent of population over 18 covered by Medicare, number of physicians per 10,000 people, ID laws and Physical Examination Requirement laws. All regressions control for state and year fixed effects, and quadratic state specific trends. All regressions are weighted by the population in the relevant age group. Robust standard errors clustered at state level are reported in parentheses.

$* * * \mathrm{p}<0.01, * * \mathrm{p}<0.05, * \mathrm{p}<0.1$ 


\section{APPENDIX}

\section{Data Appendix}

\section{Treatment Episode Data Set (TEDS)}

The opiates and synthetics category (code 7) includes buprenorphine, codeine, Hydrocodone, hydromorphone, meperidine, morphine, opium, oxycodone, pentazocine, propoxyphene, tramadol, and any other drug with morphine-like effects.

The stimulants category includes. The stimulants category (code 12) includes methylphenidate and any other stimulants.

The benzodiazepine category (code 13) includes alprazolam, chlordiazepoxide, clonazepam, clorazepate, diazepam, flunitrazepam, flurazepam, halazepam, lorazepam, oxazepam, prazepam, temazepam, triazolam, and other unspecified benzodiazepines.

The non-benzodiazepine tranquilizers (code 14) include meprobamate, tranquilizers, etc. The barbiturates (code 15) include amobarbital, pentobarbital, phenobarbital, secobarbital, etc.

The other non-barbiturate sedatives or hypnotics category (code 16) includes chloral hydrate, ethchlorvynol, glutethimide, methaqualone, sedatives/hypnotics, etc. Inhalants (code 17) include chloroform, ether, gasoline, glue, nitrous oxide, paint thinner, etc.

The over the counter medications (code 18) category includes aspirin, cough syrup, diphenhydramine and other anti-histamines, sleep aids, and any other legally obtained non-prescription medication. 
Table A1. The impact of PDMPs on treatment admissions for abuse of Rx drugs

\begin{tabular}{|c|c|c|c|c|}
\hline & Ages $12-17$ & Ages 18-24 & Ages $25-4$ & Ages $\geq 45$ \\
\hline & \multicolumn{4}{|c|}{ Panel A. Control border effects } \\
\hline PDMP, $\mathrm{t}-2$ & $\begin{array}{l}-0.452 \\
(0.291)\end{array}$ & $\begin{array}{l}-3.328 \\
(2.552)\end{array}$ & $\begin{array}{c}-1.323 \\
(1.721)\end{array}$ & $\begin{array}{c}-0.202 \\
(0.187)\end{array}$ \\
\hline Mandatory PDMP, $\mathrm{t}-2$ & $\begin{array}{c}-0.142 \\
(0.391)\end{array}$ & $\begin{array}{l}-5.275^{*} \\
(2.822)\end{array}$ & $\begin{array}{l}-2.750 \\
(1.869)\end{array}$ & $\begin{array}{l}-0.315^{*} \\
(0.173)\end{array}$ \\
\hline Border PDMP, $\mathrm{t}-2$ & $\begin{array}{c}0.003 \\
(0.011)\end{array}$ & $\begin{array}{c}0.017 \\
(0.061)\end{array}$ & $\begin{array}{c}0.037 \\
(0.032)\end{array}$ & $\begin{array}{c}0.002 \\
(0.004)\end{array}$ \\
\hline \multirow[t]{2}{*}{ Mandatory Border PDMP, $\mathrm{t}-2$} & $\begin{array}{c}0.013 \\
(0.010)\end{array}$ & $\begin{array}{l}0.143^{*} \\
(0.082)\end{array}$ & $\begin{array}{c}0.067 \\
(0.055)\end{array}$ & $\begin{array}{c}0.007 \\
(0.005)\end{array}$ \\
\hline & \multicolumn{4}{|c|}{ Panel B. Unweighted } \\
\hline PDMP, t-2 & $\begin{array}{l}-0.388 \\
(0.389)\end{array}$ & $\begin{array}{l}-0.689 \\
(3.519)\end{array}$ & $\begin{array}{l}-0.198 \\
(1.839)\end{array}$ & $\begin{array}{l}-0.149 \\
(0.152)\end{array}$ \\
\hline \multirow[t]{2}{*}{ Mandatory PDMP, $\mathrm{t}-2$} & $\begin{array}{c}0.527 \\
(0.322)\end{array}$ & $\begin{array}{l}-3.394 \\
(4.289)\end{array}$ & $\begin{array}{l}-2.372 \\
(2.246)\end{array}$ & $\begin{array}{l}-0.271 \\
(0.227)\end{array}$ \\
\hline & \multicolumn{4}{|c|}{ Panel C. Exclude zero cells } \\
\hline PDMP, $\mathrm{t}-2$ & $\begin{array}{l}-0.559^{*} \\
(0.322)\end{array}$ & $\begin{array}{l}-3.925 \\
(2.757)\end{array}$ & $\begin{array}{l}-1.726 \\
(1.924)\end{array}$ & $\begin{array}{l}-0.249 \\
(0.200)\end{array}$ \\
\hline Mandatory PDMP, $\mathrm{t}-2$ & $\begin{array}{l}-0.264 \\
(0.393)\end{array}$ & $\begin{array}{c}-5.749 * * \\
(2.801)\end{array}$ & $\begin{array}{l}-3.283^{*} \\
(1.765) \\
\end{array}$ & $\begin{array}{c}-0.354 * * \\
(0.162)\end{array}$ \\
\hline
\end{tabular}

All regressions use 2003-2014 data. All regressions control for percent male, percent black, percent other race in age group and state age structure of population: age 12-17 (omitted), age 18-24, age 25-44, age over 45), state unemployment rate, per capita income, percent of population over 18 covered by Medicaid, percent of population over 18 covered by Medicare, number of physicians per 10,000 people, ID laws and Physical Examination Requirement laws. All regressions control for state and year fixed effects, and quadratic state specific trends. Regressions in panels 1 and 3 are weighted by the population in the relevant age group. Robust standard errors clustered at state level are reported in parentheses.

$* * * \mathrm{p}<0.01,{ }^{* *} \mathrm{p}<0.05,{ }^{*} \mathrm{p}<0.1$ 
Table A2. The impact of PDMPs on treatment admissions for alcohol abuse

\begin{tabular}{lcccc}
\hline \hline & Ages 12-17 & Ages 18-24 & Ages 25-44 & Ages $\geq 45$ \\
\hline & & & & \\
PDMP, t-2 & $-2.136^{*}$ & -4.643 & -1.920 & -0.926 \\
& $(1.101)$ & $(3.403)$ & $(3.914)$ & $(1.572)$ \\
Mandatory PDMP, t-2 & 0.840 & -6.195 & -2.935 & -1.017 \\
& $(1.254)$ & $(4.720)$ & $(4.109)$ & $(1.692)$ \\
Obs. & 612 & 612 & 612 & 612 \\
\hline \hline
\end{tabular}

All regressions use 2003-2014 data. All regressions control for percent male, percent black, percent other race in age group and state age structure of population: age 12-17 (omitted), age 18-24, age 25-44, age over 45), state unemployment rate, per capita income, percent of population over 18 covered by Medicaid, percent of population over 18 covered by Medicare, number of physicians per 10,000 people, ID laws and Physical Examination Requirement laws. All regressions control for state and year fixed effects, and quadratic state specific trends. All regressions are weighted by the population in the relevant age group. Robust standard errors clustered at state level are reported in parentheses.

$* * * \mathrm{p}<0.01, * * \mathrm{p}<0.05, * \mathrm{p}<0.1$ 
Table A3. The impact of PDMPs on treatment admissions for abuse of over-the-counter medication

\begin{tabular}{lcccc}
\hline \hline & Age 12-17 & Age 18-24 & Age 25-44 & Age $\geq 45$ \\
\hline & & & & \\
PDMP, t-2 & -0.016 & 0.152 & 0.148 & 0.026 \\
& $(0.091)$ & $(0.171)$ & $(0.146)$ & $(0.025)$ \\
Mandatory PDMP, t-2 & -0.007 & 0.056 & 0.067 & 0.013 \\
& $(0.047)$ & $(0.061)$ & $(0.060)$ & $(0.009)$ \\
Obs. & 612 & 612 & 612 & 612 \\
\hline \hline
\end{tabular}

All regressions use 2003-2014 data. All regressions control for percent male, percent black, percent other race in age group and state age structure of population: age 12-17 (omitted), age 18-24, age 25-44, age over 45), state unemployment rate, per capita income, percent of population over 18 covered by Medicaid, percent of population over 18 covered by Medicare, number of physicians per 10,000 people, ID laws and Physical Examination Requirement laws. All regressions control for state and year fixed effects, and quadratic state specific trends. All regressions are weighted by the population in the relevant age group. Robust standard errors clustered at state level are reported in parentheses.

$* * * \mathrm{p}<0.01, * * \mathrm{p}<0.05, * \mathrm{p}<0.1$ 